\title{
Egg size and hybrid syndrome-dependent embryo mortality in Chironomus hybrids (Diptera: Chironomidae)
}

\author{
KLAUS HÄGELE and MONIKA KASPER-SONNENBERG \\ Ruhr-Universität Bochum, Medizinische Fakultät, Abteilung für Molekulare Humangenetik, 44780 Bochum, Germany; \\ e-mail: KHaegele-Witten@t-online.de
}

Key words. Chironomus thummi, Ch. thummi thummi, Ch. thummi piger, hybrid syndromes, Rud, HLE, egg size, embryo mortality, postzygotic reproductive isolation

\begin{abstract}
Female hybrids of the cross Chironomus t. thummi $q \times$ Ch. t. piger o which are largely affected by the sterility inducing Rud syndrome were backcrossed with males of both parental strains. The aim of the study was to provide information about those egg volumes that are insufficient for a normal embryogenesis and to ascertain whether in the hybrids the lethally small egg size represents a new abnormal trait of the Rud syndrome. The egg masses obtained contain eggs of very different sizes with volumes ranging from $0.5 \mathrm{nl}$ to $3.49 \mathrm{nl}$. Embryo mortality is unusually frequent in those eggs of the backcrosses and of the parental strains that have volumes sinailer than $1.5 \mathrm{nl}$. An egg volume of $1.5 \mathrm{nl}$ represents in Ch. thummi the lower limit for those volumes that are sufficient for a normal embryogenesis. Mortality increases with decreasing egg size, reaching $100 \%$ in backcross eggs with volumes of $0.99 \mathrm{nl}$ and smaller. Small egg size is a new trait of the Rud syndrome affected thummi $q \times$ piger $\delta$ hybrids. This trait is part of a postzygotic reproductive isolation barrier between thummi and piger and manifests first in the backcrosses. Most backcross eggs show volumes between $1.5 \mathrm{nl}$ and $2.99 \mathrm{nl}$. Within this volume range the amount of mortality does not depend upon egg volume. Here, embryo death is great in the backcrosses but normal in the parental strains. The high frequency of embryo death in the backcrosses must be predominantly due to the action of the Rud syndrome and a second hybrid syndrome, called HLE syndrome. Since further characteristic traits of these syndromes could be detected in surviving backcross individuals, the study demonstrates the occurrence of the syndromes in this generation also. Therefore, the postzygotic reproductive isolation mechanism of both hybrid syndromes is effective in the hybrids and in their progeny as well.
\end{abstract}

\section{INTRODUCTION}

Within egg masses of Chironomus t. thummi and Ch. $t$. piger a correlation exists between egg size and egg number: The smaller the egg number the smaller the eggs (Strenzke, 1959). Up to now no information has been available about the extent to which the egg size may be reduced without lethal consequences to embryonic development. During recent investigations, female hybrids of the cross direction Ch. t. thummi o $\times$ Ch. t. piger of were found to produce a large scale of eggs of different sizes including lethally small egg sizes. These hybrids are affected by the germ line specific Rud syndrome. The aberrant traits of this syndrome are no or rudimentary gonads, chromosome aberrations in germ cells, a different condensation behavior of paternal and maternal chromosomes in meiosis and a strongly reduced chiasma frequency in males (Hägele, 1984; Hägele \& Oschmann, 1987; Hägele \& Lachmann, 1992). The Rud syndrome operates as one efficient postzygotic reproductive isolation barrier between thummi and piger populations if a breakdown of the prezygotic isolation mechanism has occurred. The latter is due to a different swarming behavior of the two Chironomus subspecies (Miehlbradt \& Neumann, 1976). Another postzygotic reproductive isolation barrier is established by the HLE syndrome. This syndrome occurs also in the $F 1$ hybrids but reciprocally to the Rud syndrome in the Ch. t. piger $q \times C h$. t. thummi $\delta$ cross direction. The abnormal traits of the HLE syndrome are a high frequency of embryo mortality, chromosome aberrations, malformations, and a heterogeneous development (Hägele, 1984, 1995; Hägele et al., 1995).

To determine the egg sizes that are too small for a normal embryonic development and larval hatch, we backcrossed Rud syndrome affected thummi o $\times$ piger $\delta$ female hybrids with males of the parental thummi and $p i$ ger strains. We compared the volumes of the backcross eggs and the frequency of the corresponding embryonic mortality with that of the hybrids and the parental stocks. The aim of the study was to ascertain whether in Chironomus hybrids lethally small egg sizes represent a new and abnormal trait of the Rud syndrome. If so, this trait would be the only one of the Rud syndrome that manifests in the hybrid progeny, although it originates in the gonads of the hybrids themselves like the other Rud syndrome traits. The trait concerned is then part of the syndrome specific postzygotic reproductive isolation barrier between thummi and piger (Hägele, 1999; Hägele et al., 1995). Investigation of the backcrosses could additionally show whether both syndromes occur in the hybrid progeny and contribute once more to a reproductive isolation.

\section{MATERIAL AND METHODS}

Two Chironomus thummi subspecies, Ch. thummi thummi*, strain HL, and Ch. thummi piger, strain E, were used. The chironomids were reared in mass cultures according to Hägele (1975)

* Chironomus thummi Kieffer may be a synonym of Chironomus riparius Meigen if one follows the proposal of Credland (1973). 
TABLE 1. Eggs investigated at the consecutive developmental stages E0, E1, E2, E3 or E4. Hours after egg deposition are indicated, the developmental temperature was $21^{\circ} \mathrm{C}$.

\begin{tabular}{|c|c|c|c|c|c|c|c|}
\hline $\begin{array}{l}\text { Cross } \\
q \times 0\end{array}$ & $\begin{array}{l}\text { Egg No., stage } \\
\text { E } 0: \cong 0-1 \mathrm{~h}\end{array}$ & $\begin{array}{c}\text { Egg No., stage } \\
\text { E } 1: \cong 4-6 \mathrm{~h}\end{array}$ & $\begin{array}{c}\text { Egg No., stage } \\
\text { E } 2: \cong 15 \mathrm{~h}\end{array}$ & $\begin{array}{c}\text { Egg No., stage } \\
\text { E } 3: \cong 30 \mathrm{~h}\end{array}$ & $\begin{array}{c}\text { Egg No., stage } \\
\text { E } 4: \cong 40 \mathrm{~h}\end{array}$ & $\begin{array}{l}\text { No. of egg } \\
\text { masses used }\end{array}$ & $\begin{array}{r}\text { Total No } \\
\text { of eggs }\end{array}$ \\
\hline$t h \times t h$ & 210 & 627 & 588 & 620 & 645 & 18 & 2,690 \\
\hline$p i \times p i$ & 107 & 638 & 597 & 630 & 655 & 11 & 2,627 \\
\hline$(t h \times p i) \times t h$ & & 880 & 1,823 & 652 & 443 & 41 & 3,798 \\
\hline$(t h \times p i) \times p i$ & & 575 & 1,213 & 1,835 & 1,256 & 47 & 4,879 \\
\hline
\end{tabular}

at a temperature of $21^{\circ} \mathrm{C}$. They were identified on the basis of the banding pattern of their polytene chromosomes (Keyl \& Strenzke, 1956; Hägele, 1970).

The chironomids provided for crossing experiments were reared under standardized feeding, temperature, aerating and lighting conditions (Hägele, 1975). Freshly hatched larvae of each egg mass were placed into a plastic dish filled with aerated pond water and covered by a glass cap. The larvae were fed a paste made of powdered stinging nettles and water. The rearing temperature was $21^{\circ} \mathrm{C}$ during a time schedule of $16 \mathrm{~h}$ of illumination and $8 \mathrm{~h}$ darkness. Hybridization was done in mating cages with the dimensions of $25 \mathrm{~cm} \mathrm{(l)} \times 25 \mathrm{~cm} \mathrm{(w)} \times 60 \mathrm{~cm} \mathrm{(h)}$. For each cross 5-7 virgin females were isolated from the plastic dishes immediately after emergence and added to the mating cages to a fivefold number of earlier collected males. Female hybrids of the cross thummi $q \times$ piger of were backcrossed either with thummi or piger males. Egg masses were removed from the mating cage immediately after deposition. Embryonic development of the eggs within each egg mass was synchronized by permanently aerating the culturing water. The eggs were grouped into the developmental stages E0, E1-E4 (Table 1). The stages E1-E4 correspond essentially to the ones published in Keyl (1958) and Strenzke (1959). Only those egg masses were analyzed where at least one egg started embryogenesis. The eggs of each egg mass were counted and the length and diameter of the eggs was measured with an ocular micrometer adapted to the dissecting stereo microscope. For an estimation of the egg size the egg volume was chosen. The egg volume represents the actual egg size more closely than does the egg length or the index of egg length/egg diameter. Since the eggs have an ellipsoid shape the egg volume (V) in nanoliters (nI) was estimated by the formula $V=(D / 2)^{2} \times L / 2 \times 4 / 3 \pi$, where $D$ is the egg diameter, and $\mathrm{L}$ the egg length (Gellert et al., 1981).

Fourth instar backcross larvae were studied for the occurrence of traits of the HLE syndrome such as malformations and chromosome aberrations. Salivary gland chromosomes were prepared and Orcein stained and studied for HLE syndrome specific chromosome aberrations with a Zeiss photomicroscope
II (Hägele, 1984). To test for the occurrence of the Rud syndrome the adults were sexed and the ovaries of the females dissected out $12 \mathrm{~h}$ after emergence and before egg deposition. Egg deposition occurs usually 20-24 h after emergence. Ovaries with no, few or small eggs were taken as representative for rudimentary developed gonads caused by the Rud syndrome (Hägele, 1987).

\section{RESULTS}

Freshly laid eggs of the developmental stage E0 of Chironomus $t$. thummi and $C h$. $t$. piger show an average volume of $1.572 \mathrm{nl}$ with an egg length of $283 \mu \mathrm{m}$ and an egg diameter of $103 \mu \mathrm{m}$, respectively. It is not possible to decide whether an egg in this stage will begin embryonic development or not. Hence, for the study of egg size dependent embryo mortality, routine measurements of the eggs were started about four to six hours after egg deposition in the E1 stage when the blastoderm occurs (Miall \& Hammond, 1900). Measurements were also taken at later embryonic stages E2, E3 and E4 which differ in their developmental time from one another as indicated in Table 1.

After backcrossing only about $9 \%$ of the thummi $q \times$ piger of females lay egg masses. These egg masses contain on average less than $10 \%$ of the 500-700 eggs normally present in egg masses of the parental strains. Eggs within the same egg mass of a hybrid female show, in general, abnormally large size differences (Fig. 1). Fig. 2 reveals the frequencies of the egg volumes of eggs laid by hybrid females after backcrossing with piger and thummi males and by thummi and piger females after intrastrain mating. The egg volumes were arranged into six different volume categories. A comparison of the egg volumes of the successive developmental stages E1 to E4 showed that volumes increased with progressive embryonic de-
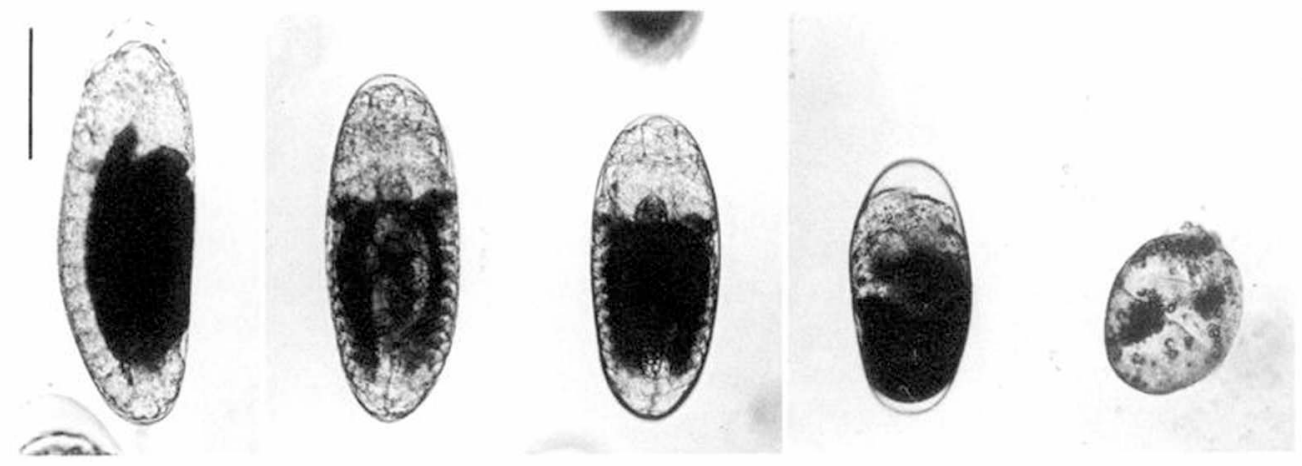

Fig. 1. Different egg sizes within the same egg mass of a backcrossed (Ch.t.thummi $\rho \times C h . t$. piger $\left.\delta^{*}\right)$ female with a $C h . t$. thummi male. The three largest eggs were in the developmental stage $\mathrm{E} 3$, they had volumes of $\mathrm{V}=2.54 \mathrm{nl}, \mathrm{V}=2.11 \mathrm{nl}$, and $\mathrm{V}=1.87$ $\mathrm{nl}$. The two smallest eggs died, their volumes were $\mathrm{V}=1.17 \mathrm{nl}$ and $\mathrm{V}=0.96 \mathrm{nl}$. The bar represents $100 \mu \mathrm{m}$. 


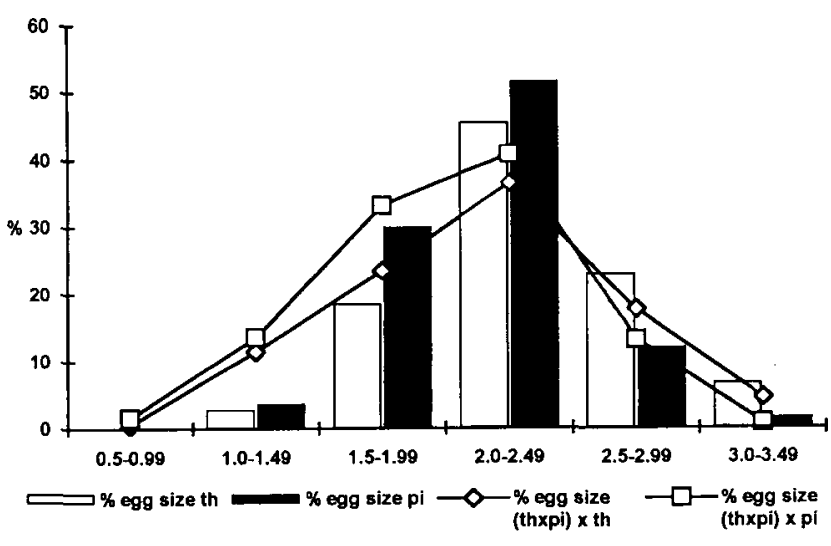

Fig. 2. Egg sizes (volume in $\mathrm{nl}$ ) observed in egg masses of Ch. t. thummi $(=\mathrm{th})$, Ch. $t$. piger $(=\mathrm{pi})$, and of $(t h \times p i)$ females backcrossed with th and pi males. Measurements of the egg length and egg diameters were done at the developmental stage E1, E2, E3 and E4. The calculated volumes are arranged in six different volume categories reaching from $0.5 \mathrm{nl}$ to $3.49 \mathrm{nl}$. The frequencies of the egg volumes in per cent.

velopment (data not presented). Although the egg volumes in the E1 stage differ only slightly between thummi $(\mathrm{V}=1.891 \mathrm{nl})$ and piger $(\mathrm{V}=1.883 \mathrm{nl})$, the average increase of the egg volumes until the E4 stage is in piger about $24 \%$ and in thummi $38 \%$, respectively. The $14 \%$ larger increase in thummi eggs originates presumably from the $27 \%$ larger genome of thummi in comparison to piger (Keyl, 1965). The somewhat different frequencies of the egg volumes of thummi and piger in the same egg volume categories of Fig. 2 may be due to these genomic differences. The eggs of piger and of the (thummi $q \times p i$ ger $\left.{ }^{*}\right)$ females crossed with piger males occur in the two egg volume categories with $1.5-1.99 \mathrm{nl}$ and 2.0-2.49 $\mathrm{nl}$ more frequently than do the genomically larger eggs of thummi and of the (thummi $q \times$ piger $\delta$ ) females crossed with thummi males. In the next two volume categories with larger egg volumes an opposite situation can be observed: The genomically smaller eggs of piger and of the (thummi $q \times$ piger $\delta$ ) $q \times$ piger $\delta$ cross hold the minority.

Most eggs of the egg masses of thummi and piger, as well as of the backcrosses, belong to the volume category of $2.0-2.49 \mathrm{nl}$ (Fig. 2). In this category the average number of backcross eggs is lower in comparison to the eggs of the pure thummi and piger strains. However, if the categories with smaller egg volumes are considered a reverse relationship concerning the egg number of the aforementioned crosses becomes evident: Backcrosses produce smaller eggs more frequently than the parental strains. The volume category with the smallest egg volumes only contains eggs of the backcrosses (Fig. 2). A statistical test using $\mathrm{r} \times \mathrm{c}$ contingency tables (Zar, 1974) demonstrates that the distribution of the egg size frequency presented in Fig. 2 is significantly different between the backcrosses and the intrastrain crosses. The difference found between (thummi $q \times$ piger $\delta$ ) $q \times p i$ ger $\delta$ and piger $\times$ piger eggs is $\chi^{2}=41.512, \mathrm{v}=5, \mathrm{p}<$ 0.001 , and between (thummi $q \times$ piger $\delta$ ) $q \times$ thummi $\delta$ and thummi $\times$ thummi eggs $\chi^{2}=65.324, \mathrm{v}=5, \mathrm{p}<0.001$.

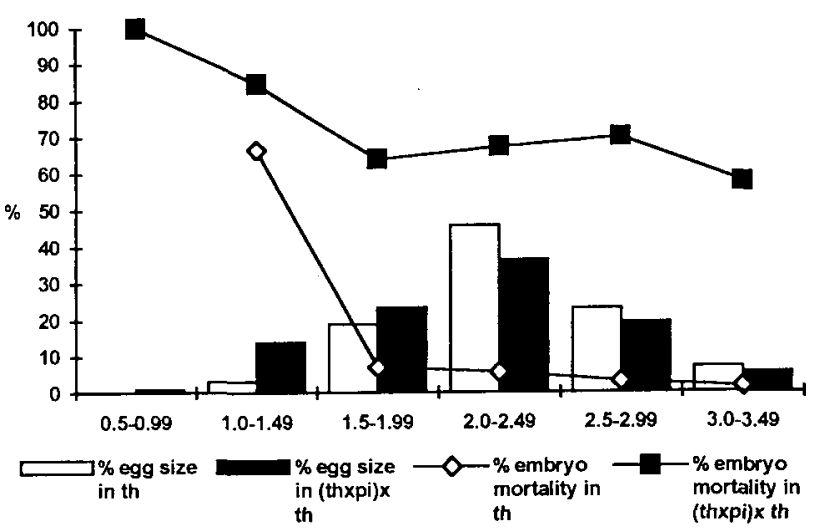

Fig. 3. Per cent frequencies of egg volumes (in $\mathrm{nl}$ ) and of embryo mortality in Ch. t. thummi (= th) and in the backcross of (Ch. t. thummi $+\times$ Ch. t. piger ot) hybrid females with $C h . t$ thummi males within six volume categories. The data were obtained from the developmental stages E1, E2, E3 and E4.

If the frequencies of the egg volumes in the four genetically different types of egg masses are compared with the frequencies of egg mortality in the corresponding egg masses the following dependence becomes obvious (Figs $3,4)$ : In those eggs of the backcrosses showing egg volumes of $0.99 \mathrm{nl}$ and smaller, embryo mortality is always $100 \%$. Such small egg sizes do not occur in the pure thummi and piger strains. In the next volume category with larger eggs $(\mathrm{V}=1.0-1.49 \mathrm{nl})$ embryo lethality in the backcross eggs is reduced by a factor of $0.82-0.84$ but shows still extraordinarily high values. Within this category also eggs of the parental strains begin to appear exhibiting a high proportion of embryo death, too. Until the volume category of 1.5-1.99 $\mathrm{nl}$ embryo lethality is further decreasing in all egg mass types. In this category and in the next three categories with again larger egg volumes $(\mathrm{V}=2.0-3.49 \mathrm{nl})$ the amount of embryo lethality remains nearly constant in the backcrosses at a level of $65 \%$ and $50 \%$, respectively. This is demonstrated by the small and nearly identical multiplication factors of the $\mathrm{X}$ in the linear regression equations ( $Z a r, 1974)$. The equation calculated for (thummi $+\times$ piger $\left.\delta^{*}\right)+9 \times$ thummi $\delta$ is $\mathrm{Y}=$ $3.2 \mathrm{x}-72.9$, and $\mathrm{Y}=3.8 \mathrm{x}-13.8$ for (thummi $+\times$ piger $\delta$ ) $q \times$ piger $\delta$. A very similar development of embryo mortality is also true for both the thummi and piger strains, but here mortality remains constant at a significantly lower level (Figs 3, 4). These results demonstrate that, for eggs from all four crosses, embryo mortality is not related to egg size at volumes of $1.5 \mathrm{nl}$ or above.

In the four egg volume categories described above where the egg size does not further determine embryo mortality, strong differences in the frequency of embryo death between the backcrosses and the parental strains become evident. In the parental strains the small number of embryos dying is normal and amounts to between $2 \%$ and $7 \%$ per egg volume category. In the backcrosses, however, an embryo lethality occurs that is in the average about 12 times larger than in the parental strains. Even between both backcross directions differences exist in egg mortality of more than $10 \%$. The differences are statistically significant $\left(\chi^{2}=94.25, f=3, p<0.001\right)$. These 


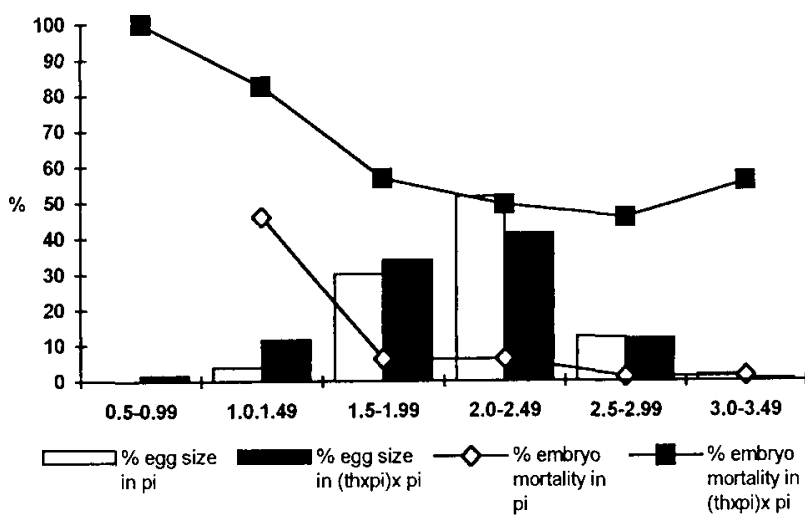

Fig. 4. Per cent frequency of egg volume (in nI) and of embryo mortality in Ch. t. piger (= pi) and in the backcross of $(C h$. t. thummi $q \times C h$. . piger $\delta$ ) females with $C h$. $t$. piger males in six egg volume categories. The data were obtained from the developmental stages E1, E2, E3 and E4.

observations suggest that in the backcrosses the large amount of embryo lethality may be due to the action of the Rud and the HLE hybrid syndromes. The investigation of the (thummi $q \times$ piger $\delta) ~ \& \times$ thummi of backcrosses showed abnormal traits of the HLE as well as of the Rud syndrome: HLE syndrome specific malformed larvae and salivary gland chromosome aberrations could be found, and, additionally, rudimentarily developed ovaries characteristic of the Rud syndrome (Table 2). The HLE syndrome is known to produce, in addition to its aforementioned traits, more than $75 \%$ embryo mortality in piger eggs fertilized with thummi sperm. Therefore, it can be assumed that the high embryo mortality observed in the eggs of the (thummi $q \times$ piger $\delta$ ) females backcrossed with thummi males may at least partially also be due to the action of the HLE syndrome. In the (thummi ? $\times$ piger $\delta) ~ \& \times$ piger $\delta$ backcross on the other hand, numerous rudimentarily developed ovaries were found, while HLE caused defects such as malformations and chromosome aberrations were rare or not observed (Table 2). Embryo mortality is also high but smaller in relation to the reciprocal backcross. With respect to the frequency of the damaging events it is evident that the aberrant traits of the HLE syndrome clearly occur more often in (thummi $q \times$ piger of) $q \times$ thummi ot than in the (thummi $q \times$ piger $\delta) ~ q \times$ piger $\delta$ cross. An inverse relationship exists concerning the frequency of the rudimentary ovaries of the Rud syndrome.

\section{DISCUSSION}

Investigation of eggs produced by Rud syndrome affected female hybrids after backcrossing and by the two parental thummi and piger strains showed that the smallest eggs are exclusively obtained after backcrossing. Amongst those small eggs with a slightly greater volume, the eggs of the backcrosses occur more frequently than those of the pure thummi and piger strains. These frequency differences begin to disappear when egg sizes are considered to which most of the eggs of the parental strains and of the backcrosses belong and which, therefore, represent the normal average egg sizes. Thus, it is evident that small egg volumes display a specific character of the two backcrosses studied. Since the rearing conditions were the same differences in nourishment of the females cannot be responsible for the egg size differences (Wheeler, 1996). Because $97 \%$ of the backcrossed females are affected by the Rud syndrome and develop rudimentary ovaries it may be inferred that their small eggs are a result of the Rud syndrome action. Small egg sizes should therefore represent a trait of the Rud syndrome. This trait manifests itself, by contrast to the other Rud syndrome traits, first in the backcross generation but, like the other traits, originates in the hybrids (Hägele, 1984; Hägele \& Lachmann, 1992; Hägele \& Oschmann, 1987, 1989).

Investigation of the egg sizes and the embryo mortality showed that a relationship exists between egg size and embryo death. Starting with an egg volume smaller than $1.5 \mathrm{nl}$ embryo mortality is more frequent the smaller the egg volume. This effect is independent from the genetic constitution of the eggs since it can be observed in both backcrosses as well as in the two parental strains. The smallest eggs with an embryo mortality of $100 \%$ occur only in the backcrosses. From these results it can be concluded, that in the chironomids studied here, the egg volume of $1.5 \mathrm{nl}$ represents a border line beneath which the frequency of successful embryonic development depends on egg size.

TABLE: 2. Frequency of traits of the HLE and Rud syndrome in the reciprocal thummi $\times$ piger hybrids and in two backcrosses. The th $\times t h$ and $p i \times p i$ crosses served as a control. The HLE syndrome is here characterized by a high embryo mortality and an increased occurrence of malformations and chromosome aberrations. A high amount of rudimentarily developed ovaries is specific for the Rud syndrome.

\begin{tabular}{ccccc}
\hline $\begin{array}{c}\text { Cross } \\
\text { \% }\end{array}$ & $\begin{array}{c}\text { \% eggs with embryo } \\
\text { mortality }\end{array}$ & $\begin{array}{c}\text { \% larvac with } \\
\text { malformations }\end{array}$ & $\begin{array}{c}\text { \% larvae with } \\
\text { chromosome aberrations }\end{array}$ & $\begin{array}{c}\text { \% adults with } \\
\text { rudimentary ovaries }\end{array}$ \\
\hline$t h \times t h^{*}$ & 11.3 & 0.04 & 0.84 & 1.75 \\
$p i \times p i^{*}$ & 7.3 & 0.02 & 1.24 & 0.85 \\
$t h \times p i^{*}$ & 8.2 & 0.05 & 0 & 97.73 \\
$p i \times t h *$ & 83.1 & 4.80 & 10.04 & 0.83 \\
$(t h \times p i) \times t h$ & 73.9 & 1.48 & 2.60 & 37.50 \\
$(t h \times p i) \times p i$ & 65.1 & 0.94 & 0 & 43.80 \\
\hline
\end{tabular}

*Smmarized data of Hägele (1984, 1987, 1995) and Hägele \& Oschmann (1989). 
Egg size dependent embryo lethality does not occur in eggs with volumes larger than $1.5 \mathrm{nl}$. This is evidenced by the fact that in this volume range a change in egg size does not further alter the frequency of embryo mortality (see also regression equations) as is the case in eggs with smaller volumes. Within the above mentioned volume range the considerable difference in the frequency of embryo mortality between the backcrosses and the parental strains is surprising. Here, embryo mortality is about 15 times greater in the backcrosses. This means that more than $60 \%$ of the $($ thummi $q \times$ piger $\delta) ~ q \times$ thummi $\delta$ eggs and about $50 \%$ of the (thummi $q \times$ piger $\delta) ~ i \times p i-$ ger $\delta$ eggs are lethally damaged even if the embryo death usually observed in all chironomid egg masses $(2-7 \%)$ is subtracted. We suggest that this high level of damage is due to the action of the HLE and the Rud syndromes since traits of both syndromes were observed in backcross larvae and adults. In germ cells of (thummi $+\times$ piger 0 ) hybrid males Rud syndrome induced chromosome aberrations occur causing partial infertility (Hägele \& Oschmann, 1987). If such events also take place in the germ cells of the (thummi $q \times$ piger 0 ) hybrid females, a fraction of non or incomplete developing eggs must be expected after backcrossing. This injury hits the two backcross directions to the same extent since both have the same female parents. In the (thummi $q \times$ piger $\delta) ~ \% \times$ thummi $\delta$ cross the extent of a Rud syndrome induced embryo death is enhanced by the HLE syndrome. The latter syndrome is already known for its egg mortality inducing effect in the (piger $q \times$ thummi $\delta$ ) hybrids (Hägele, 1995). A basic presupposition for the HLE syndrome seems to be the fusion of a maternal piger wit' a paternal thummi genome in the egg. Such an event occurs in $6.25 \%$ of the eggs of (thummi o $\times$ piger $\delta$ ) females fertilized by thummi sperm because this percentage of nybrid oocytes receive only piger chromosomes during meiosis assuming a crossing over incidence of zero. Thus, a HLE syndrome caused embryo lethality in the (thummi $q \times$ piger $\delta) ~ q \times$ thummi $\delta$ cross may be responsible for the $10 \%$ greater embryo death in comparison to the (thummi $q \times$ piger of) $+\times$ piger of backcross, a backcross where a HLE constellation is not apparent. Whether in the latter cross the occurrence of few malformed larvae indicates a mild HLE syndrome needs to be further investigated.

It may be questioned whether the large amount of embryo mortality in the backcrosses is not only due to the supposed crosses but also to parthenogenetically developing eggs. Parthenogenesis has occasionally been observed in eggs of five members of the genus Chironomus (Beermann, 1955; Grodhaus, 1971). In Ch. pallidivittatus and Ch. tentans it gives rise to embryos which are not viable. We never observed developing eggs laid by (thummi o $\times$ piger $\left.\delta^{*}\right)$ hybrid females which had no mating possibility. In this study we used a fivefold majority of males in the mating cages. Mating between thummi and piger or backcrossing occured without any problems. Successful crossing is also indicated by the observation that all the supposed backcross individuals that we analyzed for sali- vary gland chromosome aberrations showed the haploid chromosome complement of those males we used for backcrossing.

Ch. t. thummi and Ch. $t$. piger are reproductively isolated by a prezygotic isolation mechanism, that is a different swarming behavior of the two subspecies (Miehlbradt \& Neumann, 1976). In spite of this mechanism a few hybrids were found in the wild (Hägele, 1999). After a breakdown of the prezygotic isolation barrier a postzygotic isolation barrier operates on the resulting hybrids. This barrier is represented by the two nonreciprocally and in opposite cross directions occurring HLE and Rud syndromes. The Rud syndrome minimizes fertility of the (thummi $q \times$ piger $\delta$ ) hybrids by producing rudimentary gonads, while the HLE syndrome damages the (piger $q \times$ thummi $\delta$ ) cross by a strong embryo mortality (Hägele et al., 1995). The data presented in this paper show that reproductive isolation factors also act upon the backcrosses and even on those adults that survived the syndrome attacks on embryo development. The surviving backcrosses may be affected by Rud syndrome induced rudimentary ovaries and by HLE syndrome caused chromosome aberrations and malformations.

The results of this study touch the controversially discussed question whether $C h$. t. thummi and Ch. t. piger should be regarded as full species or as subspecies (Keyl \& Strenzke, 1956; Strenzke, 1959; Scharf, 1973; Credland, 1973; Miehlbradt \& Neumann, 1976; Lindeberg \& Wiederholm, 1979). One important argument in favor of the species status is that both forms have not been found to hybridize in nature even at areas where they are sympatric. Miehlbradt \& Neumann (1976) report a different swarming behavior of thummi and piger in the wild resulting in a strong species specific reproductive isolation. If the natural swarming behavior of thummi and piger is, for example, impeded during rearing in the laboratory, both forms hybridize without any difficulty. Surprisingly, nearly all the above authors mentioned that the hybrids are fully fertile and viable. Here it must be questioned whether such a situation would occur if the two Chironomus forms have already evolved to the species level. On the other hand, even a strong isolation of the thummi and piger swarms can be disturbed by a sudden wind drift so that individuals of both forms may contact and occasionally hybridize. When the hybrids are fully fertile and viable it is improbable that a supposed species status would then be maintained. Recently we detected two hybrids in nature at a geographic region in Eastern Germany where no hybrids could have escaped from laboratories. This observation, and our findings that after hybridization a second reproductive isolation mechanism occurs resulting in a strongly reduced viability and fertility of the hybrids, argues against the taxonomic classification as full species. It may indicate that this second isolation mechanism evolved to prevent along with the first one a genetic recombination between the diverging thummi and piger. Our above findings are valid for different populations since we collected our strains at France, Greece and Ger- 
many. Cytogenetic and molecular genetic studies also indicate a very close relationship of thummi and piger. Since the work of Keyl \& Strenzke (1956) and Keyl (1965) it is known that thummi and piger are not separated by inversions, as is the case between other Chironomus species. In fact, homologous thummi and piger polytene chromosomes are homosequential. In a small number of interspersed pericentric bands a size differentiation between homologous thummi and piger bands is demonstrable on the cytogenetic (Keyl \& Strenzke, 1956; Keyl, 1965) and molecular level (Schmidt, 1984). However, between different thummi populations similar differentiation processes are observed in some homologous bands (Keyl, 1957; Hägele, 1970). Therefore, the cytogenetically observable differences between thummi and $p i-$ ger are not species specific. In our opinion the taxonomic status of the two chironomids should be freshly discussed under a sophisticated consideration of the cytogenetic and genetic results. We assume that both Chironomus forms are involved in a process towards species formation and that they should, therefore, further be treated as subspecies as originally proposed by Keyl \& Strenzke (1956).

\section{REFERENCES}

Becrmann W. 1955: Cytologische Analyse eines Camptochironomus-Artbastards. Kreuzungsergebnisse und die Evolution des Karyotyps. Chromosoma 7: 198-259.

CREDland P. 1973: The taxonomic status of Chironomus riparius Meigen and Chironomus thummi Kieffer (Diptera: Chironomidae). J. Nat. Hist. 7: 209-216.

Gellert W., Küstner H. \& Neuber S. 1981: Lexikon der Mathematik. VEB, Bibliographisches Institut, Leipzig, 306 pp.

Grodiaus G. 1971: Sporadic parthenogenesis in three species of Chironomus (Diptera). Can. Entomol. 103: 338-340.

HÄGELE K. 1970: DNS-Replikationsmuster der SpeicheldrüsenChromosomen von Chironomiden. Chromosoma 31: 91-138.

HägElE K. 1975: Chironomus. In King R.C. (ed.): Handbook of Genetics. Vol. 3. Plenum Press, New York, pp. 269-278.

HÄGELE K. 1984: Different hybrid effects in reciprocal crosses between Chironomus thummi thummi and $\mathrm{Ch}$. th. piger including spontaneous chromosome aberrations and sterility. Genetica 63: 105-111.

HÄGELE K. 1987: Non-reciprocal gonadal dysgenesis in Chironomus thummi hybrids: temperature sensitivity of female sterility. Dev. Genet. 8: 17-26.

HÄGELE K. 1995: The HLE hybrid dysgenesis syndrome in the midge Chironomus thummi: differences in the dysgenic potential between strains. Genetica 96: 239-245.

HüGELE K. 1999: Hybrid syndrome induced postzygotic reproducive isolation: A second reproduction barrier in Chironomus thummi (Diptera: Chironomidae). J. Zool. Syst. Evol. Res. 37: 161-164.
Hägele K. \& OsCimann B. 1987: Non-reciprocal gonadal dysgenesis in hybrids of the chironomid midge Chironomus thummi. III. Germ line specific abnormalities. Chromosoma 96: $50-54$

HÄGELE K. \& OSCIIMANN B. 1989: Non-reciprocal gonadal dysgenesis in hybrids of the chironomid midge Chironomus thummi. II. Gonadal dysgenesis inducing chromosomes. Genetica 78: 185-193.

HÄGELE K. \& L $\Lambda$ CIIMANN J. 1992: In the Rud hybrid dysgenesis syndrome of Chironomus hybrids maternal chromosomes condense earlier than paternal chromosomes. Chromatin 1: $59-67$.

HüGele K., Nyinus E. \& Oscimann B. 1995: Heterogeneous development of hybrids of the midge Chironomus thummi: $A$ third trait of the HLE syndrome contributing to reproductive isolation. Biol. Zbl. 144: 243-251.

KeYL H.-G. 1957: Untersuchungen am Karyotypus von Chironomus thummi I. Mitteilung. Karte der SpeicheldrüsenChromosomen von Chironomus thummi thummi und die cytologische Differenzierung der Subspecies Ch. th. thummi und $\mathrm{Ch}$. th. piger. Chromosoma 8: 739-756.

KEYL H.-G. 1958: Untersuchungen am Karyotypus von Chironomus thummi II. Mitteilung. Strukturveränderungen an den Speicheldrüsen-Chromosomen nach Röntgenbestrahlung von Embryonen und Larven. Chromosoma 9: 441-483

KeyL H.-G. 1965: Duplikationen von Untereinheiten der chromosomalen DNS während der Evolution von Chironomus thummi. Chromosoma 17: 139-180.

Keyl H.-G. \& Strenzkr: K. 1956: Taxonomie und Cytologie von zwei Subspezies der Art Chironomus thummi. Z. Naturforsch. (B) 11: 727-735

LiNDEBERG B \& WIEDERHOLM T. 1979: Notes on the taxonomy of European species of Chironomus (Diptera: Chironomidae). Entomol. Scand. (Suppl.) 10: 99-116.

Miall L.C. \& HAMmOND A.R. 1900: The Structure and Life History of the Harlequin Fly (Chironomus). Clarendon Press, Oxford, pp. 59-61.

MieIlLBRADT J. \& Neumann D. 1976: Reproduktive Isolation durch optische Schwarmmarken bei den sympatrischen Chironomus thummi und Ch. piger. Behavior 58: 272-297.

SCII^Rl: B. 1973: Experimentelle ökologische Untersuchungen an Chironomus thummi und Chironomus piger (Diptera, Chironomidae). Arch. Hydrobiol. 56: 225-244.

Schmidt E.R. 1984: Clustered and interspersed repetitive DNA sequence family of Chironomus. The nucleotide sequence of the Cla-elements and various flanking sequences. J. Mol. Biol. 178: 1-15.

StrEnZKE K. 1959: Revision der Gattung Chironomus Meig. I. Die Imagines von 15 norddeutschen Arten und Unterarten. Arch. Hydrobiol. 56: 1-42.

WHEELER D. 1996: The role of nourishment in oogenesis. Annu. Rev. Entomol. 41: 407-431.

ZAR J.D. (ed.) 1974: Biostatistical Analysis. Prentice-Hall, New York, pp. 59-208.

Received January 15, 1999; accepted May 12, 1999 